\title{
ROLE OF PRONASE-RESISTANT PEPTIDE SEGMENTS OF THE ANTITUMOR PROTEIN ANTIBIOTICS, AUROMOMYCIN AND MACROMOMYCIN, IN STABILIZING CYTOCIDAL ACTIVITY OF THE CHROMOPHORE MOIETIES TO CARCINOMA CELLS*
}

\author{
Nobuhiko Miwa, Satoshi Mizuno and Suehiko Okamoto \\ Department of Antibiotics, National Institute of Health \\ Kamiosaki, Shinagawa-ku, Tokyo 141, Japan
}

(Received for publication August 18, 1982)

\begin{abstract}
The free chromophores isolated from the antitumor protein antibiotics, auromomycin (AUR) and macromomycin (MCR), were rapidly inactivated by incubation in serum-containing medium at $37^{\circ} \mathrm{C}$ in the dark with respect to cytocidal activity to human lung carcinoma A549 cells. Under the same conditions, the intact antibiotics, their pronase-hydrolysates and reconstituents from the chromophores and apo-proteins were stable. Intact and reconstituted AUR and MCR were more resistant to pronase digestion than the apo-proteins. The analyses of the pronase-hydrolysates of AUR and MCR by SDS-polyacrylamide gel electrophoresis and ultrafiltration showed that the antibiotics (13 kilodaltons $(\mathrm{kDa})$ ) were degraded to produce peptide fragments $(1 \sim 3 \mathrm{kDa})$ in which most cytotoxicity of the pronase-hydrolysates resided. The pronase-hydrolysates exhibited a differential cytocidal activity to normal diploid fibroblasts (WI38), their SV40-transformants (VA13) and carcinoma cells (A549) of human lung origin as was observed for the intact antibiotics.

These results indicate that specific interaction between the chromophores and the pronaseresistant peptide segments $(1 \sim 3 \mathrm{kDa})$ of the protein moiety stabilizes the cytocidal activity of the chromophores and also protects the peptide segments from pronase digestion.
\end{abstract}

Auromomycin (AUR) and macromomycin (MCR) are antitumor antibiotics ${ }^{1,2)}$ composed of polypeptides of similar amino acid compositions (molecular weight of 11,700) and non-protein chromophores. $^{2 \sim 5)}$ The pronase-hydrolysates of AUR have been shown to inhibit the growth of mouse lymphoblastoma cells and cause strand scission of isolated PM2 DNA to the same degree as the intact antibiotic. ${ }^{8)}$ We have found that most of the chromophores of MCR are more intensely bound than those of AUR to the protein moiety, whose major parts form antiparallel $\beta$-pleated sheets. ${ }^{7)} \quad$ Parts of the protein moiety interacting with the chromophores have not been characterized. In the preceeding paper, ${ }^{8)}$ we have shown that AUR and MCR exhibit a differential cytocidal activity to normal diploid fibroblasts, their SV40-transformants and carcinoma cells of human lung origin, and this differential cytotoxic effect is solely attributed to the chromophore moieties.

In this paper, we show that the chromophores of AUR and MCR are stabilized by interacting with the $1 \sim 3$ kdalton $(\mathrm{kDa})$ pronase-resistant peptide segments of the protein moieties, which are protected from pronase digestion by interacting with the chromophores. We also show that the pronase-hydrolysates of AUR and MCR, which are as stable as the intact antibiotics, exhibit a differential cytocidal acti-

* This work was in part presented at the 102nd Annual Meeting of the Pharmaceutical Society of Japan, April 3, 1982.

Abbreviations: AUR, auromomycin; MCR, macromomycin; hyd, pronase-hydrolysate; chr, chromophore; apo, apo-protein; rec, reconstituent; TNBS, 2,4,6-trinitrobenzenesulfonic acid; PSS, physiological salt solution; $\mathrm{D}_{10}, 10 \%$ survival dose. 
vity to normal, transformed and carcinoma cells.

\section{Materials and Methods}

Materials

AUR and MCR were generously provided by Kanegafuchi Chem. Ind. Co., Ltd., Takasago, Hyogo, Japan. Pronase E (10 tyrosine units/g) was purchased from Kaken Chem. Co., Tokyo. 2,4,6-Trinitrobenzenesulfonic acid sodium salt (TNBS) of the biochemical grade was obtained from Wako Pure Chem. Ind. Ltd., Osaka.

\section{Cell Culture}

Three monolayer human lung cell lines, normal diploid fibroblasts WI38, ${ }^{9)}$ their SV40-transformants VA13 ${ }^{10)}$ and carcinoma cells A54911), were cultivated as described in the preceding paper. ${ }^{8)}$

Determination of Cytotoxicity of AUR, MCR and Their Derivatives

The cytotoxic effect of the antibiotics was determined by the direct colony formation assay as previously described..$^{8)}$ The cells were treated with the antibiotics for 2 hours at $37^{\circ} \mathrm{C}$ in the dark. After the treatment, the antibiotic-containing medium was drained and the cells were developed for 12 days in fresh medium.

\section{Hydrolysis of AUR and MCR with Pronase}

The antibiotics $(1 \mathrm{mg} / \mathrm{ml})$ were incubated with pronase $\mathrm{E}(1 \mathrm{mg} / \mathrm{ml})$ in $0.02 \mathrm{M} \mathrm{Na}$-phosphate buffer (pH 7.5) at $37^{\circ} \mathrm{C}$ for 24 hours in the dark.

\section{Extraction of Chromophores from AUR and MCR}

The chromophores of AUR and MCR were extracted from the lyophilized antibiotics with methanol and ethanol precooled at $-20^{\circ} \mathrm{C}$, respectively, in the dark as previously described. ${ }^{8)}$ Amounts of the chromophores, apo-proteins and pronase-hydrolysates were expressed as equivalent weights of intact AUR and MCR before the extraction and proteolysis.

\section{SDS-Polyacrylamide Gel Electrophoresis}

The electrophoresis was performed essentially as described by SHAPIRO et al. ${ }^{12}$ ) Fifteen percent polyacrylamide slab gels (bis: acrylamide, $0.8: 30 \mathrm{w} / \mathrm{w}$ ) were used to retain low molecular weight peptides. Cupric acetate $(0.1 \%)$ was added to dye solutions to improve staining of small peptides.

Determination of $N$-Terminal Amounts of the Pronase-hydrolysates

Concentrations of $N$-terminals produced by proteolysis were colorimetrically determined by the TNBS method, ${ }^{13)}$ by using L-leucine for calibration. The amino-group amounts were corrected by subtracting the control values of pronase alone at various incubation times.

\section{Stability of Cytocidal Activity of AUR, MCR and Their Derivatives}

The antibiotics and their derivatives $(8 \mu \mathrm{g} / \mathrm{ml})$ were preincubated at $37^{\circ} \mathrm{C}$ in Eagle MEM supplemented with $10 \%$ fetal calf serum and 10 mM HEPES (Medium I) or methanol for up to 5 hours. At various times, samples were administered to A549 cells in the logarithmic phase. After a treatment period of 40 minutes, cell survival was determined by the colony formation assay as described above. The drug concentrations were chosen to give the surviving fractions of approximately $2 \times 10^{-3}$ without preincubation: MCR and its reconstituent, $80 \mathrm{ng} / \mathrm{ml}$; chr-MCR, 390; hyd-MCR, 140; AUR and its reconstituent, 3.2; chr-AUR, 42; hyd-AUR, 5.1.

\section{Reconstitution of AUR and MCR from the Chromophores and Apo-proteins}

One volume of concentrated chromophore solutions $(100 \mathrm{mg} / \mathrm{ml})$ in methanol or ethanol was mixed with four volumes of apo-protein solutions $(12.5 \mathrm{mg} / \mathrm{ml})$. The mixtures were gently stirred at $0^{\circ} \mathrm{C}$ for 5 minutes and left at $-20^{\circ} \mathrm{C}$ for 15 minutes. This procedure was repeated once again. The solutions $(0.3 \mathrm{ml})$ were applied to Sephadex G-25M columns $(1.6 \times 5.4 \mathrm{~cm}$, PD-10, Pharmacia Fine Chem.) which had been equilibrated with PSS. Elution was performed with PSS in 4 minutes, by monitoring absorptions at 273 and $347 \mathrm{~nm}$. The procedures were performed in the dark with ice-cold solutions. 
Cytotoxicity of $<1 \mathrm{kDa}$ - and 1 $\sim 5 \mathrm{kDa}-$ Fractions of the Hydrolysates of AUR and MCR

One $\mathrm{ml}$ of the pronase-hydrolysates of AUR and MCR was diluted 10-fold with $0.02 \mathrm{M} \mathrm{Na}$-phosphate buffer, $\mathrm{pH}$ 7.5. The hydrolysates were ultrafiltered on an Amicon molecular sieve membrane, Diaflo YM5 (fractionation molecular mass: $5 \mathrm{kDa}$ ) at $5^{\circ} \mathrm{C}$ in the dark. The filtrates were ultrafiltered again on an Amicon membrane, Diaflo UM2 $(1 \mathrm{kDa})$. The condensates $(1 \sim 5 \mathrm{kDa})$ and filtrates $(<1$ $\mathrm{kDa}$ ) were incubated at $37^{\circ} \mathrm{C}$ for 1 hour in Medium I to inactivate the free chromophores that might be contained, and then administered to A549 cells.

\section{Results}

Hydrolysis of AUR and MCR with Pronase and Cytotoxicity of the Hydrolysates

AUR and MCR were treated with pronase to digest the protein moieties of the antibiotics. The intact antibiotics were degraded at a substrate-enzyme ratio of $1: 1(\mathrm{w} / \mathrm{w})$, but scarcely degraded at a ratio of 100: 1 (data not shown). Under these conditions, the materials of $6 \sim 9 \mathrm{kDa}$ were observed at zero time in SDS-polyacrylamide gel electrophoregrams (Fig. 1). AUR, MCR and their apo-proteins as well as the materials of $6 \sim 9 \mathrm{kDa}$ decreased in the course of pronase digestion. No degradation products were detected in the range of $3 \sim 6 \mathrm{kDa}$ in the presence or absence of 2-mercaptoethanol which might have reduced the disulfide bond in the molecules. These results suggest that the protein moieties degraded to below $3 \mathrm{kDa}$ after 24-hour digestion.

The apo-proteins of AUR and MCR were not detectable at the position of the intact molecules after 24-hour digestion, whereas trace amounts of intact AUR and MCR were not degraded. The greater sensitivity of the apo-proteins was also evident from the more rapid increase in free $\mathrm{N}$-terminals by peptide bond breakage with pronase (Fig. 2). The antibiotics which were reconstituted by addition of the chromophores to the apo-proteins, showed pronase-resistance comparable to that of the intact antibiotics. The results indicate that the decreased pronase-resistance of the apo-proteins was not due to protein denaturation by the alcohol treatment at the time of apo-protein preparation, but rather to loss of interaction with the chromophores.

The hydrolysates of AUR and MCR obtained by pronase digestion for 24 hours exhibited a greater

Fig. 1. SDS-Polyacrylamide gel electrophoresis of pronase-hydrolysates of AUR and MCR.

The intact antibiotics and apo-proteins were digested with pronase at $37^{\circ} \mathrm{C}$ for the indicated periods. Protein molecular weight standards are A and B chains of bovine insulin (3,000 daltons), bovine trypsin inhibitor $(6,200)$, cytochrome $c(12,300), \beta$-lactoglobulin $(18,400)$, $\alpha$-chymotrypsin $(25,700)$ and ovalbumin $(43,000)$.
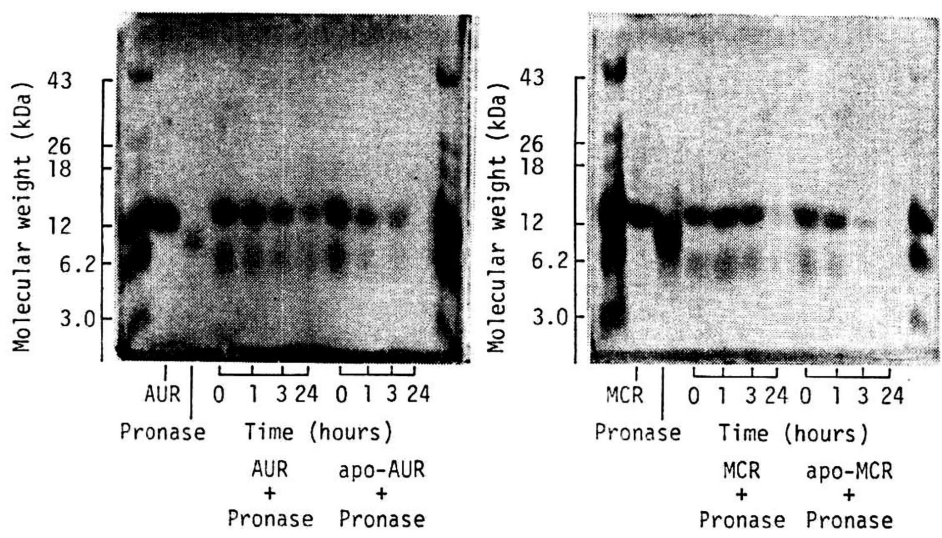
Fig. 2. Time course of increase in $N$-terminals by pronase digestion of AUR, MCR and their derivatives.

The amino groups of hydrolysates were determined by the TNBS method. Each point is the average of duplicate tubes in the experiments that were repeated twice. The molar ratio of $\mathrm{N}$-terminals in 24-hour pronase digestion to all the amino acid residues of the protein were: AUR, $46 \pm 5 \%$; apo-AUR, $84 \pm 4 \%$; rec-AUR, 52 $\pm 4 \%$; MCR, $60 \pm 3 \%$; apo-MCR, $84 \pm 3 \%$; rec-MCR, $61 \pm 5 \%$.

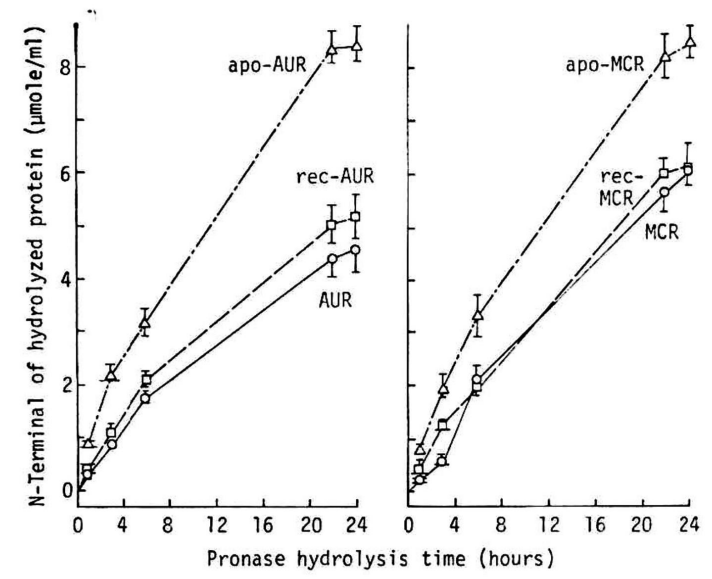

Table 1. Ten percent survival doses of AUR, MCR and their pronase-hydrolysates to three human cell lines determined by colony formation assay.

\begin{tabular}{ccccc}
\hline & \multicolumn{4}{c}{$\mathrm{D}_{10}(\mathrm{ng} / \mathrm{ml})$} \\
\cline { 2 - 5 } & AUR & $\begin{array}{c}\text { hyd- } \\
\text { AUR }\end{array}$ & MCR & $\begin{array}{c}\text { hyd- } \\
\text { MCR }\end{array}$ \\
\hline WI38 & 4.4 & 6.7 & 96 & 130 \\
VA13 & 1.9 & 2.3 & 42 & 80 \\
A549 & 1.0 & 1.3 & 27 & 45 \\
\hline
\end{tabular}

The $D_{10}$ values were obtained from Fig. 3 .

cytocidal activity to carcinoma A549 cells or SV 40-transformants VA13 than to normal WI38 cells as was observed for the intact antibiotics, although the cytocidal activity was slightly less than that of the intact antibiotics (Fig. 3). Pronase alone was not cytotoxic at $200 \mathrm{ng} / \mathrm{ml}$ (data not shown).

\section{Stability of Cytotoxicity of AUR, MCR and Their Derivatives}

Intact AUR and MCR retained most of the cytotoxic activity after incubation at $37^{\circ} \mathrm{C}$ in the serum-containing medium (Fig. 4). The chromophores were rapidly inactivated in the same medium but stable in methanol. On the other hand, the hydrolysates of the antibiotics retained most of the cytotoxic activity after incubation for 5 hours. Moreover, the inactivation kinetics suggest that the chromophore

Fig. 3. Cytotoxicity of the hydrolysates of AUR and MCR.

The antibiotics were digested with pronase at $37^{\circ} \mathrm{C}$ for 24 hours. Each point represents the average of four dishes in the experiments that were repeated twice.
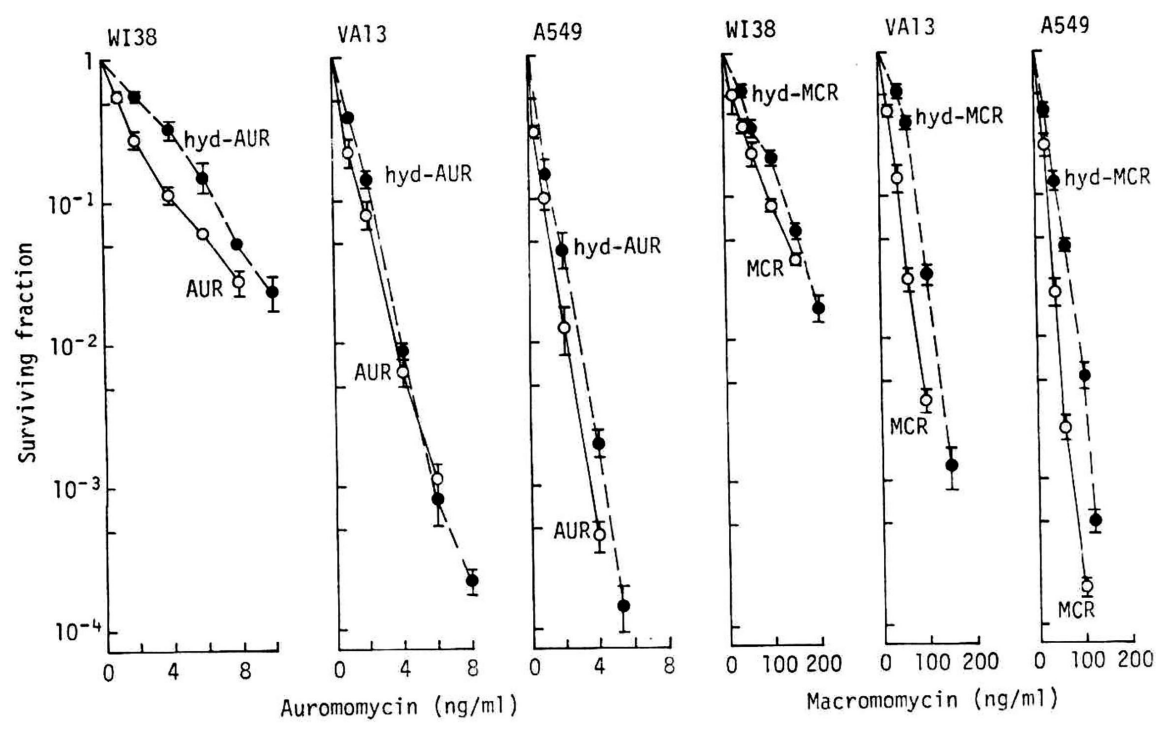
Fig. 4. Time course of inactivation of AUR, MCR and their derivatives.

The intact antibiotics, their chromophores, hydrolysates and reconstituents were preincubated for the indicated periods and assayed for their cytotoxicity to A549 cells. The ordinate means a surviving fraction calculated by standardizing the surviving fraction (about $2 \times 10^{-3}$ ) at zero time as 1 , which is designated as "relative surviving fraction". Hyd-apo-AUR and hyd-apo-MCR represent the hydrolysates of apo-proteins of AUR and MCR which were digested with pronase at $37^{\circ} \mathrm{C}$ for 8.2 hours and 13.7 hours, respectively. These digestion times were chosen to give similar extents of hydrolysis to those of 24-hour digested hydrolysates of AUR and MCR.

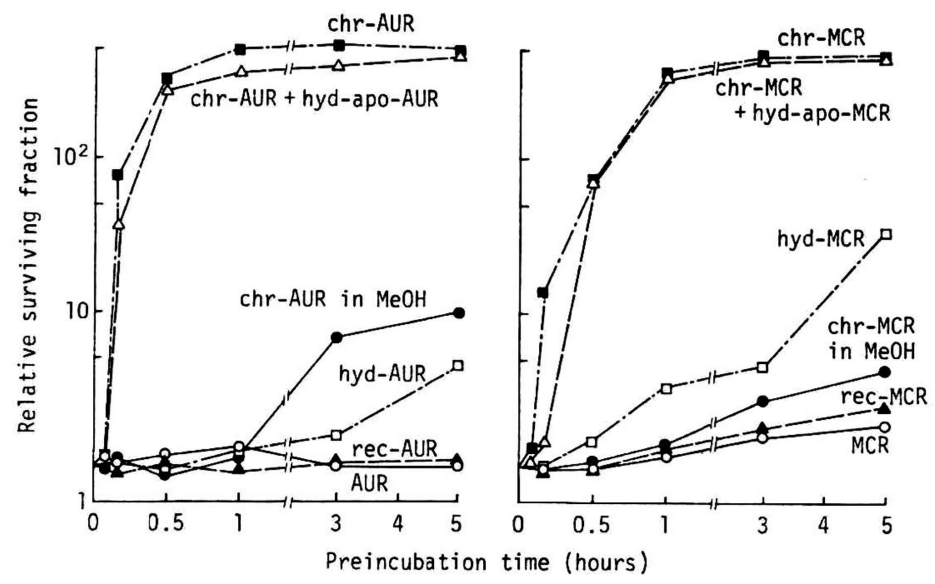

of AUR is more labile than that of MCR in methanol and in the serum-containing medium. In contrast, the intact and reconstituted forms of AUR were more stable than those of MCR. The chromophores of AUR and MCR were greatly stabilized by the apo-proteins to almost the same degree as the intact antibiotics, but not stabilized by pronase-treated apo-protein fractions. These results indicate that the chromophores are stabilized through their specific interaction with the protein moieties.

Cytotoxicity of $<1 \mathrm{kDa}$ - and

$1 \sim 5 \mathrm{kDa}$-Fractions of the Pronase-

hydrolysates of AUR and MCR

The pronase-hydrolysates of AUR and MCR were fractionated by ultrafiltration to $<1 \mathrm{kDa}$ and $1 \sim 5 \mathrm{kDa}$-fractions. The $<1 \mathrm{kDa}$-fractions showed no cytotoxicity. The $1 \sim 5 \mathrm{kDa}$-fractions of AUR and MCR exhibited $D_{10}$ 's of 1.6 and 61 $\mathrm{ng} / \mathrm{ml}$, respectively (Fig. 5), which were comparable to $D_{10}$ 's of the unfractionated hydrolysates of AUR and MCR (1.3 and $45 \mathrm{ng} / \mathrm{ml}$, respectively) (Fig. 3) and greater than $D_{10}$ 's of the intact antibiotics ( 0.9 and $25 \mathrm{ng} / \mathrm{ml}$, respectively). Free chromophores that may have remained in the hydrolysates were selectively inactivated by incubation at $37^{\circ} \mathrm{C}$ for 1 hour in the serum-containing medium (Fig. 4) before the cytotoxicity assay. The results confirmed that there existed

Fig. 5. Cytotoxicity of $<1 \mathrm{kDa}-$ and $1 \sim 5 \mathrm{kDa}-$ fractions of the hydrolysates of AUR and MCR.

The pronase-hydrolysates of AUR and MCR were fractionated to $<1$ and $1 \sim 5 \mathrm{kDa}$-fractions by ultrafiltration on the two molecular sieve membranes. The two fractions were administered to A549 cells after incubation at $37^{\circ} \mathrm{C}$ for 1 hour in Medium I. Each symbol represents the average of triplicate dishes.
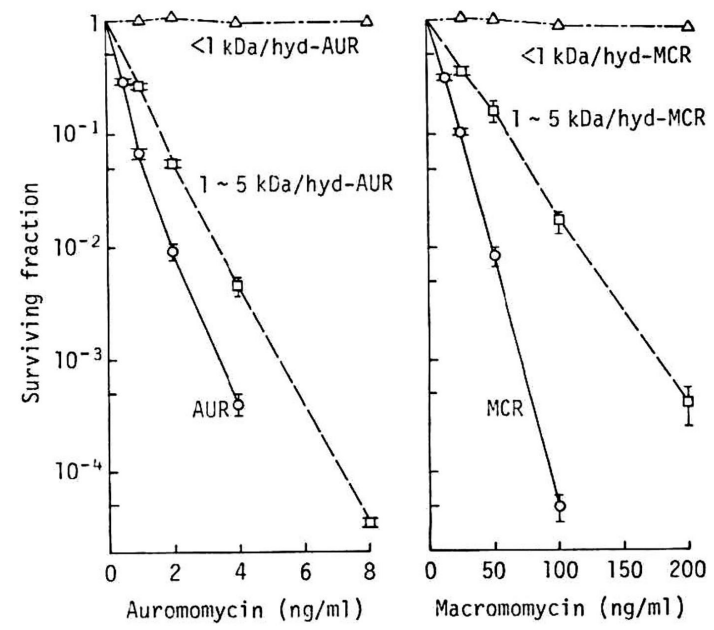
active $1 \sim 5 \mathrm{kDa}$-peptide-chromophore complexes in the pronase-hydrolysates of AUR and MCR.

\section{Discussion}

The free chromophores are labile in the serum-containing medium (Fig. 4). The free apo-proteins are also less resistant to pronase digestion than the intact antibiotics (Figs. 1 and 2). On the other hand, the intact and reconstituted antibiotics are stable in terms of cytotoxic activity and more pronase-resistant. These results indicate that specific interaction between the two components makes the chromophore moiety stable and also the protein moiety so tightly folded as to be more resistant to pronase.

The inactivation kinetics showed that the chromophore of AUR was more rapidly inactivated than that of MCR (Fig. 4). The greater instability of the chromophore of AUR is also indicated by the higher ratio of $10 \%$ survival dose $\left(D_{10}\right)$ of the chromophore of AUR to $D_{10}$ of intact AUR than that of $D_{10}$ of the chromophore of MCR to $\mathrm{D}_{10}$ of intact MCR. ${ }^{8}$ )

We have found that the IR and CD spectra of the two chromophores are different, ${ }^{7)}$ suggesting that the two chromophores are different in chemical structures. However, they may resemble each other in the light of the results by NAOI et al., ${ }^{5)}$ that the two chromophores give similar elution profiles in high pressure liquid chromatography and antibacterial spectrum.

The SDS-polyacrylamide gel electrophoregrams of the pronase-hydrolysates of the antibiotics suggest that the antibiotics are degraded to below $3 \mathrm{kDa}$ after 24-hour digestion (Fig. 1). The hydrolysates retain the greater part of the differential cytocidal activity of the intact antibiotics (Fig. 3) and are much more stable than the free chromophores (Fig. 4). However, the pronase-hydrolysates of the apoproteins, whose $\mathrm{N}$-terminal amounts are similar to those of the hydrolysates of the intact antibiotics, can not stabilize the chromophores (Fig. 4). Most of the cytocidal activity of the hydrolysates resided in the $1 \sim 5 \mathrm{kDa}$-fractions obtained by ultrafiltration (Fig. 5). The results indicate that whole protein molecule is not required for stabilizing the chromophores and peptide segments of $1 \sim 3 \mathrm{kDa}$ are satisfactory. The peptide segments may be rendered resistant to pronase through specific interaction with the chromophores.

Microbial proteins of $13 \mathrm{kDa}$ such as intact AUR and MCR may show antigenicity when injected repeatedly for cancer treatments. The pronase-hydrolysates of AUR and MCR, exhibiting differential cytotoxicity and stability comparable to those of the intact antibiotics (Table 1 and Fig. 4), may show lower immunogenicity because of their reduced molecular weights.

\section{Acknowledgments}

We wish to express our thanks to Drs. Kryoshi Watanabe and Noriyuki NaOI, Kanegafuchi Chem. Ind. Co., Ltd., for generously supplying auromomycin and macromomycin.

\section{References}

1) Chimura, H.; M. Ishizuka, M. Maeda, S. Hori, K. Kimura, J. Iwanaga, T. Takeuchi \& H. Umezawa: A new antibiotic, macromomycin, exhibiting antitumor activity and antibacterial activity. J. Antibiotics $21: 44 \sim 49,1968$

2) Yamashita, T.; N. Naol, T. Hidaka, K. Watanabe, Y, Kumada, T. Takeuchi \& H. Umezawa: Studies on auromomycin. J. Antibiotics 32: 330 339, 1979

3) Suzuki, H.; K. Miura, Y. Kumada, T. Takeuchi \& N. TANaKa： Biological activities of non-protein chromophores of antitumor protein antibiotics: auromomycin and neocarzinostatin. Biochem. Biophys. Res. Commun. 94: $255 \sim 261,1980$

4) Kalvin, D. M.; C.-H. Huang, M. A. Lischwe, E. H. Peters, A. W. Prestayko \& S. T. Crooke: DNA breakage activity of the methanol extract of auromomycin. Cancer Chemother. Pharmacol. 7: 41 50, 1981

5) Naoi, N.; T. Miwa, T. Okazaki, K. Watanabe, T. Takeuchi \& H. Umezawa: Studies on the reconstitution of macromomycin and auromomycin from the chromophore and protein moiety. J. Antibiotics 35: $806 \sim 813,1982$

6) Suzuki, H.; S. OzaWA \& N. TANaka: Urea treatment and pronase digestion of antitumor protein anti- 
biotics, auromomycin and neocarzinostatin. J. Antibiotics 33: 1545 1550, 1980

7) Mrwa, N.: Conformations of protein moieties and chromophore-protein interactions in the antitumor antibiotics, macromomycin and auromomycin, characterized by IR and CD spectral analysis. J. Antibiotics 35: $1553 \sim 1560,1982$

8) Mrwa, N.; S. Mizuno \& S. Oкамото: Differential cytotoxicity to human lung normal diploid, virustransformed and carcinoma cells by the antitumor antibiotics, auromomycin and macromomycin, and their non-protein chromophores. J. Antibiotics 36: 715 720, 1983

9) HAYFLICK, L. \& P. S. MoORHEAD: The serial cultivation of human diploid cell strains. Exp. Cell Res. 25: $585 \sim 621,1961$

10) Girardi, A. J.; D. Weinstein \& P. S. Moorhead: Ann. Med. Exp. Biol. Fenniae 44: 242 254, 1966 (Cited in The American Type Culture Collection: Catalogue of Strains. II. ed. by R. HAY, K. S. LaVAPPA, M. Macy, J. Shannon, C. Williams \& D. Stevens, p. 50, 1979)

11) Giard, D. J.; S. A. Aaronson, G. J. Todaro, P. Arnstein, J. H. Kersey, H. Dosik \& W. P. Parks: In vitro cultivation of human tumors: establishment of cell lines derived from a series of solid tumors. J. Nat. Cancer Inst. 51: 1417 1423, 1973

12) Shapiro, A. L.; E. Vinuela \& J. V. Maizel, Jr.: Molecular weight estimation of polypeptide chains by electrophoresis in SDS-polyacrylamide gels. Biochem. Biophys. Res. Commun. 28: 815 820, 1967

13) GoldFARB, A. R.: A kinetic study of the reactions of amino acids and peptides with trinitrobenzenesulfonic acid. Biochemistry 5: 2570 2575, 1966 